\title{
How to read clinical journals: XII. How you too can profit from pharmaceutical advertisements
}

\section{Steven L. Shumak, Donald A. Redelmeier}

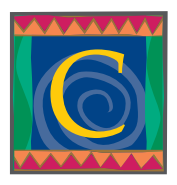

onsider the following scenario. You are perusing your favourite clinical journal and flip to an advertisement for a new drug. The left frame shows a sad looking fellow who seems older than his years. On the right panel, he looks much better and is smiling as he gazes up at a man wearing a white coat. This second man's coat and hair colour match and are equally immaculate; he looks younger than his years and exudes an aura of good health. You note that, aside from a neatly coiled stethoscope, his coat pockets are empty and contain no books, aids, scribbled notes, index cards, old "while-U-were-out" messages or other paraphernalia. Still, you deduce that he is a physician. You glance at the text beneath the panels and note that it seems to be divided into compartments. You have no trouble reading some of it: "CARDI-ERECT"TM - for all your hypertensive patients. Round-the-clock blood pressure control and NO IMPOTENCE." The remaining text is too small to make out, and you lament having left your reading glasses at the office. A blazing red line, possibly an arrow, arcs across the text from left to right and then curves upward. It reminds you of something, but you can't put your finger on it. At this point, do you consider switching your hypertensive patients to CARDI-ERECT? Do you consider putting yourself on CARDIERECT? Do you consider washing your lab coat more often? Or do you consider dying your hair?

Keeping abreast of the medical literature is a major goal for clinicians. Previously we, and others, described various approaches to reading the medical literature. ${ }^{1-4}$ However, recognizing that many clinicians obtain at least some of their knowledge from drug advertisements, ${ }^{5}$ we felt it was important to extend our recommendations and address the specifics of how to read pharmaceutical ads.

Reading drug ads might save time for the busy clinician. They take only a few moments to scan and could contain valuable information given the strict standards of modern advertising. In this article, we offer 6 key guidelines on how to approach such ads.

\section{What to read in the ad?}

Songwriter Tom Waits once said, "The big print giveth and the small print taketh away." He couldn't have characterized drug ads any better. No respectable physician should be caught dead reading 20-point lettering screaming "PRESCRIBE GLUCOPLUNGE the 6-point text is not only illegible, it's incomprehensible ("No longterm studies with PlaceboNorm ${ }^{\mathrm{TM}}$ exist to determine whether its apparent inhibition of cytochrome P450 $2 \mathrm{C} 19$ or $3 \mathrm{~A} 3$ in rhesus monkeys is persistent or merely reflects the dual kinetic profile of its major metabolites 7,7-nordeoxymetaglutamine or 5,7-paradeoxymetaglutamine, or both"). We recommend that readers focus on material printed in a 12point font $(95 \%$ confidence interval 10 to 14 ), because "that's where the money is" (well actually the money is in multinational corporations based in Switzerland but you probably knew that). Material written in bold or italics font is probably not worth reading, yet the temptation to peek may be hard to resist.

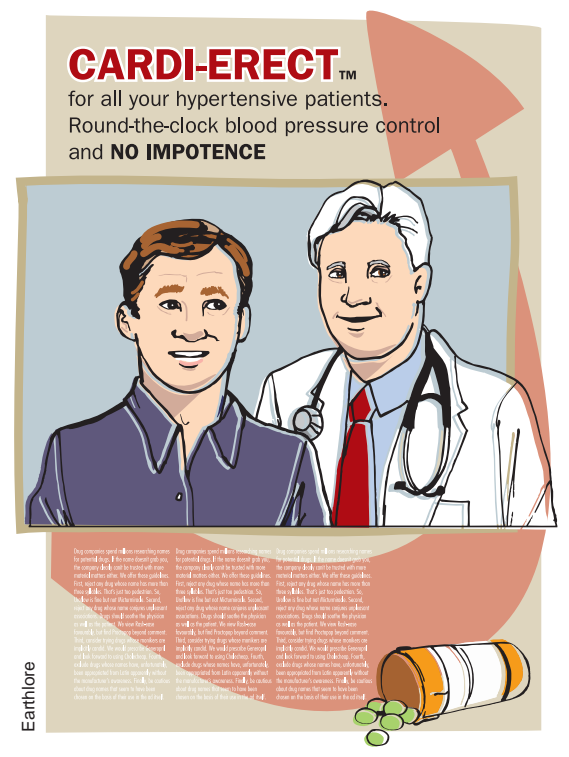

\section{Does the practice resemble yours?}

Do the patients in the ads look anything like patients in your practice? Does the doctor look like a soap opera star? Do the office furnishings resemble a Hollywood mansion? Is the drug named Superb-o-tox ${ }^{\mathrm{TM}}$ ("for people who really want to spend a lot on looking good")? Does the image convey any of the smells, noises and stresses of a real practice? If not, consider that the medication may work only in the rarefied atmosphere of idealized settings (perhaps the precise type of settings in which it was tested in clinical trials). ${ }^{6}$ If the setting does resemble your practice, please send us a letter indicating if you'd be willing to accept new associates.

\section{What "references" are cited in the ad?}

First, find the references. (Good luck - our rule of thumb is that they will usually be $3 / \theta$ pages away from the 
ad itself, where $\theta$ is the probability that you've heard of the drug. For example, if you have only a $10 \%$ feeling that you've heard of the drug, the citation will be about 30 pages away, and in some cases you might even need to flip to next month's issue.) If you are reading from a PDF on the Internet, you will likely need to reboot twice during your search.

Second, check to see if, and where, the references have been published. We appreciate the difficulty in securing publication of less-than-earthshaking results, but remain wary when the majority of references are "on file" or published as part of highly specialized proceedings ("the first annual SchleswigHolstein symposium of left patellar effects of Costalot ${ }^{\mathrm{TM}}$ "). Likewise, be wary of references to articles in journals that may exist expressly for the purpose of publishing those results. And, as linguistic Philistines, can we be blamed for harbouring doubts about results published in Fornalese por Sjkotea Ruritania Occidentalis?

Empirically, we have determined that the likelihood of references being in a mainstream clinical journal is about $\theta / 3$. Thus, if you have only a $10 \%$ feeling that you've heard of the drug, you have less than a $4 \%$ chance of finding the citation in a mainstream journal. Also, the likelihood that the search for references will be frustrating approaches $100 \%$ $(3 / \theta \times \theta / 3)$. This is known as the "HighSell-Drug Uncertainty Principle" (not to be confused with the "Folly Exclusion Principle," which merely sets a lower limit on the degree of frustration).

\section{Does the drug name grab you?}

Drug companies spend millions researching potential names for drugs. If the name doesn't grab you, the company clearly can't be trusted with more material matters. We offer these guidelines. First, reject any drug whose name has more than 3 syllables. That's just too pedestrian. So, Uroflow ${ }^{\mathrm{TM}}$ is fine but not Micturmiracle ${ }^{\mathrm{TM}}$. Second, reject any drug whose name conjures un- pleasant associations. Drugs should soothe the physician as well as the patient. We view Rash-ease ${ }^{\mathrm{TM}}$ favourably, but find Proctopop ${ }^{\mathrm{TM}}$ beyond comment. Third, consider trying drugs whose monikers are implicitly candid. We would prescribe Generopril ${ }^{\mathrm{TM}}$ and look forward to using Cholecheap ${ }^{\mathrm{TM}}$. Fourth, exclude drugs whose names have, unfortunately, been appropriated from Latin apparently without the manufacturer's awareness ("Opprobrium $^{\mathrm{TM}}$ - new for depression”). Finally, be cautious about drug names that seem to have been chosen solely for their use in the ad itself ("How much should you worry about your choice of beta-blocker? - Notatol ${ }^{\mathrm{TM}}$ ").

\section{Is the drug cost stated in the ad?}

Drugs cost a lot of money, and manufacturers should highlight rather than hide this characteristic. Should you really trust your patient's life to an antibiotic that costs "only pennies a day"? We don't think so. Indeed, if the advertised drug costs $30 \%$ more than its nearest competitor, we'd be tempted to give it a try, especially since the government is going to pick up the tab anyway. Cost consciousness has never had a place in medical research or market advertising, so why start now?

\section{Is the dosing convenient?}

Drugs ultimately need to be ordered by physicians and taken by patients, so convenience of dosing is a real concern. If Aspirin weren't as effective as it is, for example, we doubt that the $325-\mathrm{mg}$ dose would be acceptable under contemporary expectations. It would come in 100$\mathrm{mg}$ or 300-mg tablets ("in a new easyto-swallow tabcap ${ }^{\circledR}$ "). Likewise, don't even look at an ad for a drug that has to be taken more than once per day. Keep your eye open for that soon-to-be-developed once a week or once a month formulation ("Infinitum ${ }^{\mathrm{TM}}$ - one dose and you need never worry about type $4 \mathrm{~b}$ porphyrocandidopsis again"). Also, avoid drugs whose doses have to be cal- culated on the basis of body surface area, or adjusted for renal or hepatic insufficiency; these are just mistakes waiting to happen. (Indeed, many doctors aren't even good at calculating their CME credits, with their totals ending up too high.) We dream of the one-size-fits-all approach and await the release of Tedium $^{\mathrm{TM}}$ ("never adjust a dose again").

\section{Summary}

We have listed 6 guidelines that we believe will help you when reading drug ads and deciding whether or not to try a new drug. The guidelines should also make reading drug ads less intimidating and more fun. Alas, we doubt that the pharmaceutical industry will consider any of these points, because they are already way ahead of clinicians in sophistication and way ahead of regulators in resourcefulness.

Steven Shumak and Donald Redelmeier are with the Division of General Internal Medicine, Department of Medicine, Sunnybrook \& Women's College Health Sciences Centre, University of Toronto, Toronto, Ont.

Acknowledgements: Steve Shumak and Donald Redelmeier hope to receive support from the Megabucks Pharmaceuticals Corporation ("We take the 'sue' out of pharmaceuticals"). Both authors have also recently sold short on Angiodrek Inc. (makers of Clotblot ${ }^{\mathrm{TM}}$ "Why bust when you can blot!"). Earlier drafts of this article were funnier than the current version, but they generated too many haughty complaints from our colleagues Drs. Ed Etchells and Andreas Laupacis. We thank Drs. David Naylor, Bill Sibbald and Gordon Guyatt for allowing gratuitous acknowledgements.

\section{References}

1. Redelmeier DA, Shuchman M, Shumak SL. How to read clinical journals: IX. Sounding like you've read the literature when you haven't read a thing. CMA7 1998;159(12):1488-9.

2. Shumak SL, Redelmeier DA. How to read clinical journals: X. How to react when your colleagues haven't read a thing. CMA7 2000;163 (12):1570-2.

3. Redelmeier DA, Shumak SL. How to read clinical journals: XI. Everything you always wanted to know about editorials (but were afraid to ask). CMA7 2003;169(12):1323-5.

4. Haynes RB, McKibbon KA, Fitzgerald D, Guyatt GH, Walker CJ, Sackett DL. How to keep up with the medical literature: II. Deciding which journals to read regularly. Ann Intern Med 1986;105:309-12

5. Wilkes MS, Shuchman M. Pitching doctors. New York Times Magazine 1989;:88,90,126,128-9.

6. Juurlink DN, Mamdani MM, Lee DS, Kopp A, Austin PC, Laupacis A, et al. Rates of hyperkalemia after publication of the Randomized Aldactone Evaluation Study. $N$ Engl 7 Med 2004;351:543-51. 